\title{
Paraneoplastic cerebellar degeneration and limbic/ brainstem encephalopathy associated with small cell lung cancer with serum positivity for anti-Hu and multiple anti-ganglioside (GM2, GQ1b, GaLNAc-GD1a, GT1a) antibodies: A case report
}

\author{
Kazuya Nokura ${ }^{1 *}$, Tetsuharu Kako1, Fumika Azuma ${ }^{1}$, Makoto Samukawa $^{2}$, Susumu Kusunoki ${ }^{2}$ and Keiko Tanaka ${ }^{3}$ \\ ${ }^{1}$ Department of Neurology, Fujita Health University, Bantane Hospital, 3-6-10, Otohbashi Nakagawa-ku Nagoya, Aichi, Japan \\ ${ }^{2}$ Department of Neurology, Kindai University Faculty of Medicine Ohno-Higashi, Osaka-sayama, Osaka 5898511, Japan \\ ${ }^{3}$ Department of Cellular Neurobiology, Brain Research Institute, Niigata University, 1-757 Asahimachidori, Chuo-ku Niigata 951-8585, Japan
}

\begin{abstract}
Background: Anti-Hu antibodies are known to appear in paraneoplastic neurologic syndrome associated with small cell lung cancer. Miller Fisher syndrome, Guillain-Barré syndrome, and Bickerstaff brainstem encephalitis lie on the same disease spectrum, and cancer is reported to be one of the prodromal events of this disorder; the anti-GQ1b antibody is pathognomonic for diagnosing this spectrum. On the other hand, ganglioside expression in cancer cells is related to signal transmission, such as that involved in cancer growth and metastasis; furthermore, anti-ganglioside antibodies might be produced in the context of cancer.

Case presentation: A 65-year-old man without a specific history other than smoking and alcohol consumption developed difficulty speaking and walking with subacute onset. Eye movements were normal, and tendon reflexes were only partially reduced; remarkable truncal ataxia and dysarthria were observed. The patient was hospitalized for suspected Miller Fisher syndrome because he tested positive for serum GQ1b antibodies. Intravenous immunoglobulin was administered without any effect. Subsequent PET-CT examination showed positive lesions in the hilar and supraclavicular lymph nodes; a biopsy revealed a diagnosis of small cell lung cancer, and chemotherapy was initiated. Subsequently, delusions and abnormal behaviour appeared. A brain MRI showed a high signal intensity in the hippocampus, and the patient was found to be positive for serum anti-Hu antibodies. Central hypoventilation and dysphagia were also observed; we finally diagnosed him as having paraneoplastic cerebellar degeneration with limbic/brainstem encephalitis. The patient died two months later from pneumonia. It is unclear whether the antiganglioside antibody positivity in this patient followed any infection or was caused by small cell lung cancer. Whether the pathogenetic mechanisms mediated by anti-GQ1b antibodies were actually superimposed on cerebellar degeneration is unknown. These antibodies might be produced under a hyper-immune state induced by cancer.
\end{abstract}

Conclusions: This is the first reported case of cerebellar degeneration and limbic/brainstem encephalopathy accompanied by small cell lung cancer; in this case, the patient was positive for anti-Hu and multiple anti-ganglioside antibodies. The implications of anti-ganglioside antibody production in cancer should be elucidated in the future, and a screening of ganglioside antibodies should be recommended as a potential future study.

\begin{abstract}
Abbreviations: CT: Computed Tomography; FLAIR: Fluid Attenuated Inversion Recovery; GBS: Guillain-Barré Syndrome; IVIg: Intravenous Immunoglobulin; LEMS: Lambert-Eaton Myasthenic Syndrome; MFS: Miller Fisher Syndrome; BBE: Bickerstaff Brainstem Encephalitis; MRI: Magnetic Resonance Imaging; PCD: Paraneoplastic Cerebellar Degeneration; PET: Positron Emission Tomography; PNS: Paraneoplastic Neurologic Syndrome; SCLC: Small Cell Lung Cancer; SEP: Sensory Evoked Potential
\end{abstract}

\section{Background}

Paraneoplastic neurologic syndrome (PNS) is a term used to describe neurological symptoms caused by the so-called "remote effect of a tumour", excluding the direct infiltration, compression, metastasis, secondary infection and metabolic abnormality induced by the tumour in various organs [1-3]. The anti-Hu antibody, which is a classical onconeural antibody, is related to a wide range of PNSs
[3,4]. Paraneoplastic cerebellar degeneration (PCD) accounts for $24.3 \%$ of all PNSs, which is equivalent to the incidence of sensory neuropathy [5]. Many diseases cause subacute cerebellar ataxia, but Miller Fisher syndrome (MFS) should be suspected if a patient has the triad of cerebellar ataxia, ocular movement disorder and reduced tendon reflexes [6], particularly if the patient is positive for serum anti-

*Correspondence to: Kazuya Nokura, Department of Neurology, Fujita Health University, Bantane Hospital, 3-6-10, Otohbashi Nakagawa-ku Nagoya, Aichi, Japan, Tel: 81-52-321-8171, E-mail: knokura@fujita-hu.ac.jp

Key words: small cell lung cancer, paraneoplastic cerebellar degeneration, paraneoplastic limbic/brainstem encephalopathy, anti-Hu antibody, antiganglioside antibody, Miller Fisher syndrome

Received: March 15, 2020; Accepted: March 24, 2020; Published: March 27, 2020 
Nokura K (2020) Paraneoplastic cerebellar degeneration and limbic/brainstem encephalopathy associated with small cell lung cancer with serum positivity for anti$\mathrm{Hu}$ and multiple anti-ganglioside (GM2, GQ1b, GaLNAc-GD1a, GT1a) antibodies: A case report

GQ1b antibodies. The IgG antibody specific for ganglioside GQ1b is detected in the serum of approximately $80-90 \%$ of patients clinically diagnosed with MFS $[7,8]$. Atypical cases in which this triad is not present have also been reported [9]. Anti-GQ1b antibody tests are also positive in Guillain-Barré syndrome (GBS) with ophthalmoplegia or ataxia and in Bickerstaff brainstem encephalitis (BBE) [10]. Usually, the disease course is good; improvement is often observed following administration of intravenous immunoglobulin (IVIg).

Although there is no report of GQ1b expression by lung cancer cells, a positive anti-GM1 antibody test was reported in a small cell lung carcinoma patient with paraneoplastic peripheral neuronopathy [11]. Gangliosides are thought to be expressed not only on the small cell lung cancer (SCLC) cell surface but also in other cancer cells, and the presence of anti-ganglioside antibodies in the patient serum is also possible. We encountered a case in which a patient with cerebellar degeneration caused by SCLC was positive for anti-Hu antibodies and multiple anti-ganglioside antibodies, including anti-GQ1b antibodies. To the best of our knowledge, no such case has been previously reported.

\section{Case presentation}

The patient was a 65 -year-old man with a 30 cigarette/day smoking history over 45 years, and he had consumed approximately $150 \mathrm{~g}$ of alcohol every day for over 40 years. Otherwise, there was no notable medical or family history. He had no allergies and was the owner/ chef of a bar. The patient had no history of any preceding infection but reported difficulties walking due to an equilibrium disorder from (X-4) month and began to frequently fall. The patient was seen at the Neurology Department. He had cerebellar ataxia with normal eye movement and was found to be positive for anti-GQ1b antibodies (based on serum tests in a commercial laboratory); thus, an MFS or GBS-related disease was suspected, and he was hospitalized in X month, which was 14 days after his first visit at our department.

Upon admission, he was alert and scored 27/30 on the Mini Mental State Examination; there was no eye movement disorder, no diplopia, and no nystagmus, and there was a normal pupillary reaction to light. The patient's speech was ataxic and slurred. His tendon reflexes were mildly reduced in the upper limbs and patella but relatively preserved in the Achilles. All four limbs showed ataxia in the finger-to-nose and heel-knee-shin tests. In the thumb localization test, a deviation of approximately $5 \mathrm{~cm}$ was observed. Clumsiness in alternative pronation and supination of the forearms was observed, especially on the right side. The Romberg sign was not remarkable. The patient needed a cane for walking; his gait was wide based, and he fell easily. His proximal muscle strength, but not his limb strength, had declined. The Babinski sign was negative.

\section{Laboratory tests}

The complete blood counts showed mild macrocytic anaemia. The blood chemistry showed IgG at $2552 \mathrm{mg} / \mathrm{dL}$ (mildly elevated) and CRP at $2.32 \mathrm{mg} / \mathrm{L}$, and the patient was negative for C-ANCA and P-ANCA. Diabetes mellitus was ruled out, the patient's thyroid function was in the normal range, and there were no anti-thyroid antibodies. The screening tests for antibodies related to collagen disease were negative, but the antinuclear antibody titre was 80 , which was slightly elevated. The patient was negative for anti-GAD antibodies. His markers of liver and renal function were in the normal range. The tumour markers were all negative. $\mathrm{B}$ vitamins and folic acid were also within the normal range. A lumbar tap showed an initial pressure of $150 \mathrm{mmH} 2 \mathrm{O}$, and the cerebrospinal fluid had a protein concentration of $62 \mathrm{mg} / \mathrm{dL}$, a sugar concentration of $66 \mathrm{mg} / \mathrm{dL}$, and a cell count of 17/3, with a mononuclear cell count of 10 and a polynuclear cell count of 7 . The routine electrophysiological examination showed normal sensory and motor nerve conduction velocity and amplitude, with a normal sensory evoked potential (SEP) pattern. High-frequency repetitive electrical stimulation showed no waxing of the amplitude of complex muscular action potentials. The brain MRI showed no remarkable findings in the cerebrum and cerebellum (Figure 1a, 1b, 1c), but the fluid-attenuated inversion recovery (FLAIR) image showed a high signal intensity in the bilateral hippocampus, dominantly in the left (Figure $1 \mathrm{~d}$ ).

\section{Patient's course}

The positive finding of anti-GQ1b antibodies was observed before the results of the anti-Hu antibody. We first considered a diagnosis of MFS and administered $0.4 \mathrm{~g} / \mathrm{kg} \gamma$-globulin (IVIg) for 5 days without any effect; instead, the patient's symptoms became rather exacerbated. Chest CT was performed over time, and PCD was suspected because of the atypical case of MFS and the lack of an IVIg effect. Finally, swelling of the hilar and supraclavicular lymph nodes was confirmed on a chest $\mathrm{CT}$, and a subsequent PET-CT examination was performed considering the possibility of lung cancer; consequently, positive lesions were noted that appeared to have metastasized not only to the hilar but also to the right supraclavicular lymph nodes (Figure 2).

At 1.5 months after his first visit, we consulted the respiratory department. The supraclavicular lymph node was biopsied by an otolaryngologist, and we obtained a pathological diagnosis of SCLC at the T1aN3M0 stage. After admission to the respiratory department, a series of chemotherapy agents was administered. Irinotecan $(600 \mathrm{mg} /$ body weight), carboplatin ( $75 \mathrm{mg} /$ body weight) and dexamethasone (6.6 $\mathrm{mg}$ per day) were administered intravenously. Seven days after starting chemotherapy, the patient experienced oxygenation failure; we found atelectasis in the right lung, and the blood gas analysis of the patient showed hypercapnia (Figure 3a, 3b). His ventilation was temporarily

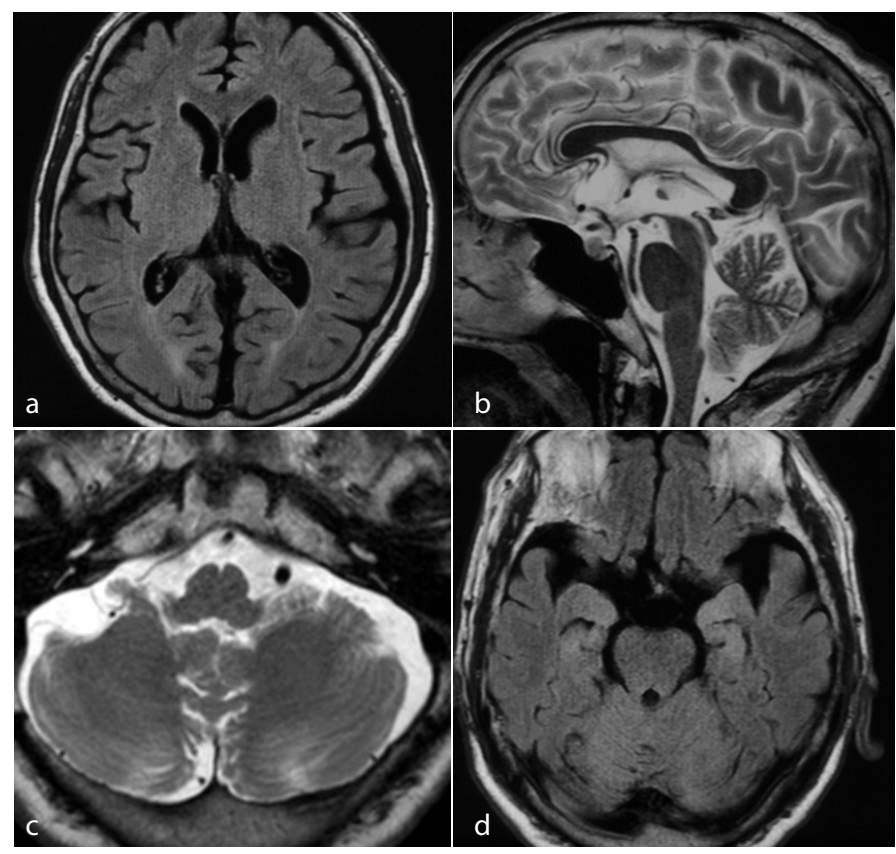

Figure 1. Brain MRI at admission a. MR in fluid-attenuated inversion recovery image (FLAIR) of the brain showing only mild posterior white matter high intensity. b. MRI T2 images showing no remarkable findings in the cerebrum and cerebellum. c. FLAIR image showing a high signal intensity in the bilateral hippocampus, dominantly on the left. 
Nokura K (2020) Paraneoplastic cerebellar degeneration and limbic/brainstem encephalopathy associated with small cell lung cancer with serum positivity for anti$\mathrm{Hu}$ and multiple anti-ganglioside (GM2, GQ1b, GaLNAc-GD1a, GT1a) antibodies: A case report

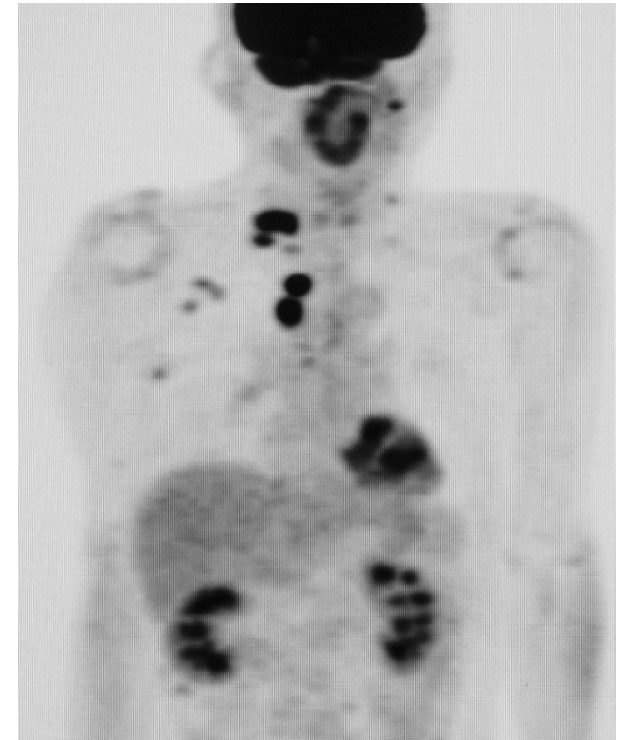

Figure 2. Positron emission tomography-CT (PET-CT) examination showing a positive image that appears to be a metastasis not only in the mediastinum but also in the right supraclavicular lymph node.

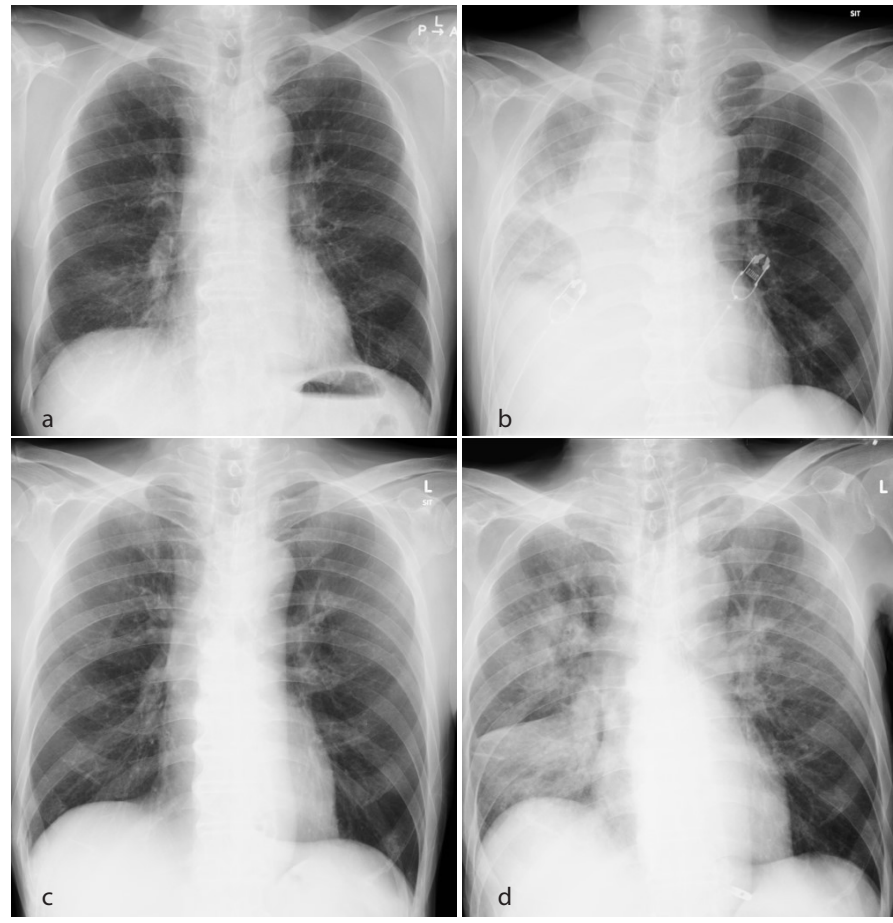

Figure 3. Series of chest roentgenograms. a. At admission (XM), there was no abnormality b. $\mathrm{X}+2 \mathrm{M}$ Decreased lucency mainly due to atelectasis in the right lung is shown $\mathbf{c}$. $\mathrm{X}+3 \mathrm{M}$ Chest X-ray image improved after treatment $\mathbf{d}$. $\mathrm{X}+6 \mathrm{M}$ Bilateral decreased lucency in the lung with right posterior lobule atelectasis is shown

assisted by a non-invasive positive-pressure ventilator. At this time, the patient was suspected of having central hypoventilation because he easily entered a hypercapnic state at night. The decreased lucency in the right lung was thought to be interstitial pneumonia induced by chemotherapy. After the administration of methylprednisolone (1000 $\mathrm{mg} \times 3$ days), prednisolone (PSL) was initiated at $40 \mathrm{mg} / \mathrm{day}$ and gradually decreased, and antibiotic therapy was administered simultaneously. Consequently, the chest X-rays showed marked improvement (Figure 3c).
After receiving 1 course of chemotherapy, IVIg was administered again, and tube feeding was started, but no neurological improvement was observed. Since the patient's dysphagia progressed into the third month, he was managed by peripheral parenteral nutrition. In the fourth month, the patient had delusions and abnormal behaviour; he had a strong desire to return home, was irritable and became violent towards the nursing staff. We used antipsychotics for sedation. We thought that all of these newly appearing symptoms would be explained by paraneoplastic neurological syndrome, and finally, the patient was found to be positive for serum anti-Hu antibodies (method described below). Two months later, his lung permeability decreased again, and he died 10 months after the first presentation due to underlying cancer and pneumonia (Figure 3d).

\section{Methods}

Serum IgM and IgG antibodies specific for nine glycolipid antigens (GM1, GM2, GM3, GD1a, GD1b, GD3, GT1b, GQ1b, and Gal-C) were tested at the laboratory of Kindai University by enzyme-linked immunosorbent assay (ELISA), as previously reported [12]. Serum obtained 170 days after neurological onset was used for the assay. Antibodies specific for $\mathrm{Hu}, \mathrm{Yo}, \mathrm{Ri}, \mathrm{CV} 2, \mathrm{Tr}, \mathrm{Ma}-2$, and amphiphysin were examined at the laboratory of Niigata University, using a ravo PNS-Blot (ravo Diagnostika GmbH, FRG).

\section{Results}

The results of the anti-ganglioside antibody and onconeural antibody tests are shown in table 1 . The following positive results were obtained: IgM GM2 (+), GalNAc-GDla (++), IgG GQ1b (++), and GT1a $(++)$ (Table 1). The anti-Hu antibody test was positive, but the tests for antibodies against Yo, Ri, CV2 (CRMP-5), Tr, Ma-2, and amphiphysin were negative (Table 2).

\section{Discussion and conclusions}

Initially, various causes of subacute onset cerebellar ataxia were considered. Although the cerebrospinal fluid test did not show protein

Table 1. Results of the anti-glycolipid antibody measurements

\begin{tabular}{|c|c|c|}
\hline Ganglioside & IgM & IgG \\
\hline GM1 & - & - \\
\hline GM2 & + & - \\
\hline GM3 & - & - \\
\hline GD1a & - & - \\
\hline GD1b & - & - \\
\hline GD3 & - & - \\
\hline GT1b & - & - \\
\hline GQ1b & - & ++ \\
\hline Gal-C & - & - \\
\hline GalNAc-GD1a & ++ & - \\
\hline GT1a & - & ++ \\
\hline GD1a/GD1b & ne & - \\
\hline
\end{tabular}

Table 2. Results of anti-neuronal antibody measurements

\begin{tabular}{|c|c|}
\hline Anti-neural antigens & results \\
\hline Yo & - \\
\hline $\mathrm{Hu}$ & + \\
\hline $\mathrm{Ri}$ & - \\
\hline $\mathrm{CV} 2(\mathrm{CRMP}-5)$ & - \\
\hline $\mathrm{Tr}$ & - \\
\hline Ma-2 & - \\
\hline amphiphysin & - \\
\hline
\end{tabular}


Nokura K (2020) Paraneoplastic cerebellar degeneration and limbic/brainstem encephalopathy associated with small cell lung cancer with serum positivity for anti$\mathrm{Hu}$ and multiple anti-ganglioside (GM2, GQ1b, GaLNAc-GD1a, GT1a) antibodies: A case report

cell dissociation, MFS was considered because of the positive serum anti-GQ1b antibody test (this result arrived first from commercial screening). However, the patient's eye movement and tendon reflexes did not meet the criteria. Furthermore, the clinical course was prolonged, and no improvement was observed even after administration of IVIg. The serum antibodies were later measured again at Kindai University, and positivity for the anti-GQ1b antibody was confirmed. In addition, IgM antibodies specific for GM2 and GalNAc-GD1a and IgG antibodies specific for GT1a were found to be positive. These antibody profiles are compatible with the diagnosis of MFS.

PCD is frequently encountered and accounts for $24 \%$ of PNS cases [5]. From a symptomatological perspective, the possibility of subacute sensory neuropathy should also be considered. However, no decreases in temperature, pain or vibration sensation were apparent during the patient's course, no remarkable Romberg sign was observed, and a normal peripheral nerve conduction test and normal SEP wave forms were obtained. Therefore, there were no obvious findings of peripheral nerve disorders.

Many studies indicate that the antigen recognized by anti-GQ1b is located in the peripheral nerves $[7,9,13]$. Although the pathology of the central nervous system in MFS seems to be controversial, there is an interesting report that the GQ1b antibody stained the cerebellum [14]. Furthermore, BBE, a disease related to GBS/MFS, has been reported to manifest central lesions on MRI [15-17].

Anti-GQ1b antibody positivity results in MFS syndrome, and anti-Hu antibody positivity results in subacute sensory neuropathy; positivity for both antibodies might further promote decreases in tendon reflexes, but interestingly, in our case, tendon reflexes were intact. A potential background of paraneoplastic encephalopathy or myelopathy might attenuate the decreased reflexes, although the Babinski sign was negative. However, the fact that a $5 \mathrm{~cm}$ deviation occurred in the thumb localization test may suggest mild disorders of the dorsal root ganglion, although in MFS cases, the thumb test is often reported to be positive [18].

During the course of the disease, the patient had delusions and abnormal behaviour, and signal abnormalities were observed in the hippocampus on MRI. Hypercapnia and a swallowing disorder were also observed, and $\mathrm{Hu}$-positive cases often show central hypoventilation $[19,20]$. Based on the patient's symptoms, a complicated paraneoplastic brainstem encephalitis could have been present.

When searching for "paraneoplastic MFS syndrome" in the literature, only one case report written in Spanish was identified [21]. Because MFS and GBS lie on the same disease spectrum, a report from a paraneoplastic GBS case should also be considered [22,23]. Cases of paraneoplastic peripheral neuropathy with a positive anti-ganglioside antibody test despite a negative onco-neural antibody test have been reported, one of which was described as MFS [24]. Kanaji et al. reported a patient with subacute sensory neuropathy caused by SCLC, which was negative for $\mathrm{Hu}$ antibodies but positive for anti-GM1 antibodies and discussed that case together with 5 cases of paraneoplastic peripheral neuropathy caused by SCLC. The antibodies found in these patients were GM1-IgM, GD1a and GM1, GM1-IgG, and GM1-IgM. However, there were no GM2, GM3, or GQ1b antibodies. Thus, a positive antiGQ1b antibody test does not necessarily suggest a complication of MFS but may be possible in the presence of cancer.

Another paper reported that the risk of GBS increases with SCLC [25-28]. Itou et al. reported that the patient was a 62-year-old woman with SCLC who was positive for anti-GM1 antibodies; however, she was negative for anti-Hu antibodies [29]. We previously reported a case of pathologically confirmed SCLC with acute-onset sensory and motor neuronopathy in which the anti-Hu antibody test was negative. In this case, the involvement of some type of autoimmunity caused by SCLC was suspected [30].

A previously reported patient with melanoma who was positive for anti-GQ1b antibodies had extraocular muscle paralysis and axonal motor neuropathy, and a response to steroids was reported [31]. This case lacked the symptoms of cerebellar ataxia, and the author was not concerned about any similarity to MFS. Fukuda et al. reported a case of limbic encephalitis associated with SCLC in which three paraneoplastic antibodies were concurrently detected [32].

Gangliosides or their gene expression levels in various cancer cells are related to signal transmission, such as that involved in cancer growth and metastasis [33,34]. Administration of anti-ganglioside antibodies may inhibit cancer growth, and monoclonal anti-ganglioside antibodies can inhibit cancer cell growth [35,36]. Furthermore, anti-ganglioside antibodies are reported to be produced in the context of cancer [37]. Several types of gangliosides have been detected with high frequency in SCLC and non-SCLC samples $[38,39]$. It may be possible to predict the presence of cancer if a patient has certain anti-ganglioside antibodies.

Paraneoplastic neurological syndrome with antibodies specific for intracellular antigens is widely considered to be a cytotoxic T cellmediated disease caused by anticancer immunity [40]. During this process, co-activation of the humoural immune mechanism is induced, and autoantibodies against onconeural antigens are produced. These neoplastic proteins are usually located in the cytoplasm or nucleus of neurons and are not targets of antibody-mediated neuronal damage [40]. Ganglioside, such as GQ1b, are well-known extracellular antigens; thus, the production of both anti-Hu antibodies and anti-GQ1b antibodies is caused by a state in which the immunological mechanism is widely activated by the cancer itself.

It is unclear whether the anti-GQ1b antibody positivity in this patient followed any infection, such as cytomegalovirus infection, since the test for IgM antibodies against GM2 and GalNAc-GD1a was positive [41] or was caused by SCLC. Unfortunately, autopsy was not performed on the patient. Whether the pathogenetic mechanisms mediated by anti-GQ1b antibodies were actually superimposed on PCD remains unknown. The possibility that anti-ganglionic antibodies may also cause paraneoplastic syndromes should be investigated in the future. IVIg is controversial because the presence of $\mathrm{Hu}$ antibodies and anti-ganglioside antibodies may improve the prognosis of cancer; unfortunately, in this case, neurological symptoms also progressed despite IVIg administration.

In conclusion, this is the first complete clinical description of a patient with PCD and limbic/brainstem encephalopathy who was positive for anti-Hu and multiple anti-ganglioside antibodies. Further accumulation of cases is needed, and the implications of antiganglioside antibody production in cancer should be elucidated in the future. A screening of ganglioside antibodies should be recommended as a potential future study.

\section{Ethics approval and consent to participate}

All studies were conducted in accordance with the content of the Helsinki Declaration. The name of the patient, initials, date of birth, date of medical treatment, place of birth, place of residence, family and family information, information on the body of the patient that could be identified, and other individual information (such as ID number at 
Nokura K (2020) Paraneoplastic cerebellar degeneration and limbic/brainstem encephalopathy associated with small cell lung cancer with serum positivity for antiHu and multiple anti-ganglioside (GM2, GQ1b, GaLNAc-GD1a, GT1a) antibodies: A case report

the relevant medical institution) that could lead to the identification of the patient are not described in this paper.

The data presented in the article included only the blood measurement values and diagnostic images. Maximum consideration was given to protecting the patient's personal information.

Antibody tests for serum IgM and IgG antibodies against nine glycolipid antigens (GM1, GM2, GM3, GD1a, GD1b, GD3, GT1b, GQ1b, and Gal-C) were conducted after obtaining informed consent from the patient. This study was also approved by the Internal Review Board of the Kindai University Faculty of Medicine.

Antibody tests for $\mathrm{Hu}, \mathrm{Yo}, \mathrm{Ri}, \mathrm{CV} 2, \mathrm{Tr}, \mathrm{Ma}-2$, and amphiphysin were conducted after obtaining informed consent from the patient. This study was approved by the Medical Research Ethics Committee of Niigata University.

\section{Consent for publication}

Written informed consent for the publication of this report and the accompanying data were obtained from the patient's bereaved family.

\section{Availability of data and materials}

All data generated or analysed during this study are included in this published article. The datasets used and/or analysed during the current study are available from the corresponding author upon reasonable request.

\section{Competing interests}

The authors have no competing interests to declare.

\section{Funding}

S Kusunoki: This study was partially supported by the Ministry of Education, Culture, Sports, Science, and Technology of Japan (Grantsin-Aid for Scientific Research, 15H04845), Practical Research Project for Rare/Intractable Diseases from the Agency for Medical Research and Development (AMED 16ek0109056h0003 and 16ek0109115h0002), and the Ministry of Health, Labour and Welfare of Japan [Health and Labour Sciences Research Grant on Rare and Intractable Diseases (Validation of Evidence-based Diagnosis and Guidelines, and Impact on QOL in Patients with Neuroimmunological Diseases)]. The role of funding is for data analysis.

K Tanaka: This work was partially supported by JSPS KAKENHI Grant Number JP 17K11477 and a Grant-in-Aid for Health and Labour Sciences Research Grants for research on intractable diseases from the Ministry of Health, Labour, and Welfare of Japan. K Tanaka has received research support from Cosmic Corporation. The role for funding is for data analysis.

\section{Author contributions}

$\mathrm{KN}$ and TK participated in the diagnosis and treatment of the patient. KN and FA contributed to the editing of the manuscript. MS, SK, and KT analysed and interpreted the patient serum data. All authors read and approved the final manuscript.

\section{Acknowledgements}

We thank Dr. M Hirose for managing the patient's respiratory care, Dr. Y Nishimura for performing the biopsy, and Dr. K Inada for the pathological diagnosis and interpretation

\section{References}

1. Henson RA, Hoffman HL, Urich H (1965) Encephalomyelitis with carcinoma. Brain 88: 449-464. [Crossref]

2. Dalmau J, Furneaux HM, Rosenblum MK, Graus F, Posner JB (1991) Detection of the anti-Hu antibody in specific regions of the nervous system and tumor from patients with paraneoplastic encephalomyelitis/sensory neuronopathy. Neurology 41:17571764. [Crossref]

3. Graus F, Keime-Guibert F, Rene R, Benyahia B, Ribalta T, et al. (2001) Anti-Huassociated paraneoplastic encephalomyelitis: analysis of 200 patients. Brain 124:11381148. [Crossref]

4. Graus F, Dalmou J, Rene R, Tora M, Malats N, et al (1997) Anti-Hu antibodies in patients with small-cell lung cancer: association with complete response to therapy and improved survival. J Clin Oncol 15: 2866-2872. [Crossref]

5. Giometto B, Grisold W, Vitaliani R, Graus F, Honnorat J, et al. (2010) Paraneoplastic neurologic syndrome in the PNS Euronetwork database: a European study from 20 centers. Arch Neurol 67: 330-335. [Crossref]

6. FISHER M (1956) An unusual variant of acute idiopathic polyneuritis (syndrome of ophthalmoplegia, ataxia and areflexia). $N$ Engl J Med 255: 57-65. [Crossref]

7. Chiba A, Kusunoki S, Obata H, Machinami R, Kanazawa I (1993) Serum anti-GQ1b IgG antibody is associated with ophthalmoplegia in Miller Fisher syndrome and Guillain-Barre syndrome: clinical and immunohistochemical studies. Neurology 43 : 1911-1917. [Crossref]

8. Ito M, Kuwabara S, Odaka M, Misawa S, Koga M, et al. (2008) Bickerstaff's brainstem encephalitis and Fisher syndrome form a continuous spectrum: clinical analysis of 581 cases. J Neurol 255: 674-682. [Crossref]

9. Kusunoki S, Chiba A, Kanazawa I (1999) Anti-GQ1b IgG antibody is associated with ataxia as well as ophthalmoplegia. Muscle Nerve 22: 1071-1074. [Crossref]

10. Odaka M, Yuki N, Hirata K (2001) Anti-GQ1b IgG antibody syndrome: clinical and immunological range. J Neurol Neurosurg Psychiatry 70: 50-55. [Crossref]

11. Kanaji N, Kume K, Mizoguchi H, Inoue T, Watanabe N, et al. (2018) Subacute Sensorimotor Neuropathy Accompanied by Anti-ganglioside GM1 Antibody in a Patient with Lung Cancer. Intern Med 57: 3289-3292. [Crossref]

12. Kusunoki S, Chiba A, Kon K, Ando S, Arisawa K, et al. (1994) N-acetylgalactosaminyl GDla is a target molecule for serum antibody in Guillain-Barre syndrome. Ann Neurol 35: 570-576. [Crossref]

13. Liu JX, Willison HJ, Pedrosa-Domellof F (2009) Immunolocalization of GQ1b and related gangliosides in human extraocular neuromuscular junctions and muscle spindles. Invest Ophthalmol Vis Sci 50: 3226-3232. [Crossref]

14. Kornberg AJ, Pestronk A, Blume GM, Lopate G, Yue J, et al. (1996) Selective staining of the cerebellar molecular layer by serum IgG in Miller-Fisher and related syndromes. Neurology 47: 1317-1320. [Crossref]

15. Odaka M, Yuki N, Yamada M, Koga M, Takemi T, et al. (2003) Bickerstaff's brainstem encephalitis: clinical features of 62 cases and a subgroup associated with Guillain-Barre syndrome. Brain 126: 2279-2290. [Crossref]

16. Michev A, Musso P, Foiadelli T, Trabatti C, Lozza A, et al. (2019) Bickerstaff Brainstem Encephalitis and overlapping Guillain-Barre syndrome in children: Report of two cases and review of the literature. Eur J Paediatr Neurol 23: 43-52. [Crossref]

17. Hacohen Y, Nishimoto Y, Fukami Y, Lang B, Waters P, et al. (2016) Paediatric brainstem encephalitis associated with glial and neuronal autoantibodies. Dev Med Child Neurol 58: 836-841. [Crossref]

18. Mori M, Kuwabara S, Fukutake T, Yuki N, Hattori T (2001) Clinical features and prognosis of Miller Fisher syndrome. Neurology 56: 1104-1106. [Crossref]

19. Graus F, Dalmau J (2012) Paraneoplastic neurological syndromes. Curr Opin Neurol 25: 795-801. [Crossref]

20. Saiz A, Bruna J, Stourac P, Vigliani MC, Giometto B, et al. (2009) Anti-Hu-associated brainstem encephalitis. J Neurol Neurosurg Psychiatry 80: 404-407. [Crossref]

21. Roquer J, Pou Serradell A (1992) [Paraneoplastic Miller-Fisher syndrome?] Neurologia 7:40. [Crossref]

22. Naveed S, Okoli K, Hollingsworth J, Kasmani R (2010) Guillain-Barre syndrome as a paraneoplastic manifestation of small-cell carcinoma of lung. South Med J 103: 156158. [Crossref] 
Nokura K (2020) Paraneoplastic cerebellar degeneration and limbic/brainstem encephalopathy associated with small cell lung cancer with serum positivity for antiHu and multiple anti-ganglioside (GM2, GQ1b, GaLNAc-GD1a, GT1a) antibodies: A case report

23. Eimil M, Benito-Leon J (2007) Guillain-Barre-like syndrome heralding small-cell lung cancer. Eur J Neurol 14: e15-16. [Crossref]

24. De Toni L, Marconi S, Nardelli E, Alberti D, Borsellino G, et al. (2004) Gangliosides act as onconeural antigens in paraneoplastic neuropathies. J Neuroimmunol 156: 178187. [Crossref]

25. Vigliani MC, Magistrello M, Polo P, Mutani R, Chio A (2004) Risk of cancer in patients with Guillain-Barre syndrome (GBS). A population-based study. J Neurol 251: 321-326. [Crossref]

26. Jung I, Gurzu S, Balasa R, Motataianu A, Contac AO, et al. (2015) A coin-like peripheral small cell lung carcinoma associated with acute paraneoplastic axonal Guillain-Barre-like syndrome. Medicine (Baltimore) 94: e910. [Crossref]

27. Tho LM, O'Leary CP, Horrocks I, Al-Ani A, Reed NS (2006) Guillain-Barre syndrome occurring after adjuvant chemo-radiotherapy for endometrial cancer. Gynecol Oncol 100: 615-617. [Crossref]

28. Ferrufino E, Camarasa A, Chiner E (2011) Guillain-Barre syndrome as an initia manifestation of small cell lung carcinoma. Arch Bronconeumol 47: 107-108. [Crossref]

29. Itou T, Enomoto S, Makita Y, Enomoto H, Kuroda K, et al. (2002) [A patient of sensorimotor neuropathy with small cell lung carcinoma and anti-GM1 antibody]. Rinsho Shinkeigaku 42: 878-880. [Crossref]

30. Nokura K, Nagamatsu M, Inagaki T, Yamamoto H, Koga H, et al. (2006) Acute motor and sensory neuronopathy associated with small-cell lung cancer: a clinicopathological study. Neuropathology 26: 329-337. [Crossref]

31. Kloos L, Sillevis Smitt P, Ang CW, Kruit W, Stoter G (2003) Paraneoplastic ophthalmoplegia and subacute motor axonal neuropathy associated with anti-GQ1b antibodies in a patient with malignant melanoma. J Neurol Neurosurg Psychiatry 74 : 507-509. [Crossref]
32. Fukuda TG, do Rosario MS, Branco RCC, Fukuda JS, de Souza ESRA, et al. (2017) Multiple paraneoplastic antibodies (anti-SOX1, anti-Hu, and anti-Amphiphysin) detected in a patient with limbic encephalitis and small cell lung cancer. Neurol India 65: 1127-1128. [Crossref]

33. Yoshida S, Fukumoto S, Kawaguchi H, Sato S, Ueda R, et al. (2001) Ganglioside G(D2) in small cell lung cancer cell lines: enhancement of cell proliferation and mediation of apoptosis. Cancer Res 61: 4244-4252. [Crossref]

34. Cavdarli S, Groux-Degroote S, Delannoy P (2019) Gangliosides: The Double-Edge Sword of Neuro-Ectodermal Derived Tumors. Biomolecules 9. [Crossref]

35. Aixinjueluo W, Furukawa K, Zhang Q, Hamamura K, Tokuda N, et al. (2005) Mechanisms for the apoptosis of small cell lung cancer cells induced by anti-GD2 monoclonal antibodies: roles of anoikis. J Biol Chem 280: 29828-29836. [Crossref]

36. Dhillon S (2015) Dinutuximab: first global approval. Drugs 75: 923-927. [Crossref]

37. Antoine JC, Camdessanche JP, Ferraud K, Caudie C (2004) Antiganglioside antibodies in paraneoplastic peripheral neuropathies. J Neurol Neurosurg Psychiatry 75: 17651767. [Crossref]

38. Fuentes R, Allman R, Mason MD (1997) Ganglioside expression in lung cancer cell lines. Lung cancer 18: 21-33. [Crossref]

39. Hayashi N, Chiba H, Kuronuma K, Go S, Hasegawa Y, et al. (2013) Detection of $\mathrm{N}$-glycolyated gangliosides in non-small-cell lung cancer using GMR8 monoclonal antibody. Cancer Sci 104: 43-47. [Crossref]

40. Tanaka K (2015) Debate on the pathogenesis of paraneoplastic cerebellar degeneration with anti-Yo antibody: T-cell mediated or antibody mediated? Clinical and Experimental Neuroimmunology 6: 222-224.

41. Yuki N, Tagawa Y (1998) Acute cytomegalovirus infection and IgM anti-GM2 antibody. J Neurol Sci 154: 14-17. [Crossref]

Copyright: (C2020 Nokura K. This is an open-access article distributed under the terms of the Creative Commons Attribution License, which permits unrestricted use, distribution, and reproduction in any medium, provided the original author and source are credited. 